\title{
Politique
}

Politique

\section{Gladys L. Symons, dir., La culture des organisations, Québec, Institut québécois de recherche sur la culture, 1988, 216 p.}

\section{Marcel Belleau}

Numéro 15, hiver 1989

Paradigmes et scientificité

URI : https://id.erudit.org/iderudit/040628ar

DOI : https://doi.org/10.7202/040628ar

Aller au sommaire du numéro

Éditeur(s)

Société québécoise de science politique

ISSN

0711-608X (imprimé)

1918-6584 (numérique)

Découvrir la revue

Citer ce compte rendu

Belleau, M. (1989). Compte rendu de [Gladys L. Symons, dir., La culture des organisations, Québec, Institut québécois de recherche sur la culture, 1988,

216 p.] Politique, (15), 132-136. https://doi.org/10.7202/040628ar d'utilisation que vous pouvez consulter en ligne.

https://apropos.erudit.org/fr/usagers/politique-dutilisation/ 
Gladys L. Symons, dir., La culture des organisations, Québec, Institut québécois de recherche sur la culture, 1988, 216 p.

Ce volume est une oeuvre collective où chacun des huit auteurs aborde une facette du concept de culture organisationnelle. Gladys L. Symons qui en a dirigé la rédaction avec la collaboration d'Yves Martin a divisé ce volume en deux parties. La première, «Perspectives» aborde la question de la définition de la culture organisationnelle et de son utilisation. La deuxième "Coups de sonde», est consacrée à l'étude de cas spécifiques au Québec, dans les secteurs public, para-public et privé. Chaque chapitre est autonome et sans lien de transition avec les autres. Cependant, le fil conducteur de la complexité de la culture organisationnelle demeure présent tout au long de l'ouvrage.

Dans la présentation du volume (p. 9), Gladys L. Symons nous enseigne que le concept de culture organisationnelle englobe les systèmes de significations symboliques que les membres des organisations comprennent et utilisent pour coordonner leurs activités. La culture, écrit-elle, est une façon de voir et d'observer qui renvoie à des symboles, des contes, des histoires, des mythes, des croyances, des idéologies, des rites, des rituels, des normes, des valeurs, etc., tout un chacun donnant une signification à la vie organisationnelle. Elle souligne l'importance du sujet d'étude en le présentant comme une voie intéressante pour la compréhension de la vie sociale via les corridors des organisations formelles. Car c'est là, dit-elle, qu'une partie 
significative de la vie quotidienne est créée, se joue et est interprétée dans notre monde moderne (p. 10).

Gladys L. Symons établit ensuite la principale critique des travaux traitant de la culture organisationnelle. L'approche conventionnelle considère la culture comme variable qui trouve son expression pratique dans le terme «culture d'entreprise». Le postulat de base à l'origine du concept suppose que les gestionnaires peuvent manipuler la culture comme ils le font pour les structures. Cela sousentend qu'il n'existe qu'une culture identifiable dans l'organisation et que cette culture d'entreprise est partagée par les gestionnaires de même que par les travailleurs. La culture d'entreprise, qui est en réalité une idéologie «managérielle», devient la culture de l'organisation. Par cette prestidigitation, on réduit au silence les voix d'autres membres de l'organisation. L'auteure nous dit avoir largement dépassé la notion de la culture comme outil de gestion et qu'il faille plutôt remettre en question la signification même du mode bureaucratique qui caractérise notre époque. Elle ajoute que: «Pour que le concept de la culture organisationnelle nous révèle des connaissances théoriques pertinentes, il faut considérer la question de la culture dans toute sa complexité» (pp. 36-77).

La culture de l'organisation comme idéologie de gestion est analysée par Joseph Smucker. Il reconnaît que les gestionnaires doivent relever le défi de s'assurer que l'engagement et la loyauté envers l'organisation existent en même temps que règne la confiance chez ses membres, d'où l'importance qu'a la culture aujourd'hui, grâce, précisément, à la vogue actuelle de l'individualisme. Il s'agirait, dans sa perspective «managérielle», d'une nouvelle tentative s'ajoutant à une longue histoire d'efforts divers visant à concilier les attentes de l'individu «irrationnel» et les exigences «rationnelles» de l'organisation.

Omar Aktouf donne des exemples et des contre-exemples de la communauté de vision au sein de l'entreprise. Il nous identifie le bon «Cascades» et les méchantes brasseries de Montréal et d'Algérie. Il nous rappelle que le système de représentation de l'ouvrier s'alimente très directement à son rapport aux conditions immédiates d'existence et à la mémoire précise de faits du passé, récent ou non, donnant une indication exacte du fossé entre ce qui est dit de lui comme partenaire 
et ce qui est fait de lui comme outil de production. Donc, l'«ingénierie» de la culture organisationnelle ne doit pas devenir un fantasmatique substitut au vrai partage que sous-entend toute véritable communauté.

Le résultat d'une étude de plus de 60 ans de vie organisationnelle du Canadien national, nous est livré par Michaela Firsirotu. Cette étude indique que les facteurs de contingence façonnent la culture d'une organisation. Elle a mis en évidence que des facteurs de contingence semblables (monopole réglementé, service public national, investissement élevé de capital) se traduisent par des cultures similaires, en dépit de différences majeures de contextes sociaux et d'influences historiques. Elle a aussi constaté que les changements majeurs discontinus se produisant dans l'entreprise (passage d'un régime de réglementation à un régime de commerce libre, par exemple) ont entraîné des modifications plutôt lentes dans la structure et la culture de l'entreprise. L'étude a aussi démontré que les acteurs principaux percevaient les changements de contexte à travers le filtre des valeurs et résultats existants. Finalement, elle montre la possibilité d'une hétérogénéité de postulats culturels au sein d'une même organisation et insiste sur le fait que la culture organisationnelle peut jouer un rôle puissant et déterminant même lorsque ses postulats sont contradictoires.

Daniel Latouche, pour sa part, démystifie cet Olympe du pouvoir que constitue le Cabinet du premier ministre (CPM) du Québec de 1976 à 1980. Le regard froid de l'approche traditionnelle, fût-il psycho-institutionnel ou structurel, ne peut, nous dit-il, rendre compte de la réalité d'organisations qui baignent aussi profondément dans le symbolisme (p. 170). Il nous donnerait l'impression que le CPM est une organisation fort peu intégrée, sans culture dominante et dont les éléments culturels majeurs viennent confirmer un climat d'incapacité d'agir.

Au contraire, l'approche culturelle, selon Latouche, nous permet d'envisager le CPM comme un rouage important dans le processus de construction étatique. Le Cabinet contribue à transformer l'autorité personnelle du Prince en un pouvoir d'État en l'appuyant sur une prétention à la compétence que permet la fréquentation quotidienne de multiples conseillers. Il permet à la «tête» de l'État d'obtenir une 
plus grande visibilité et de multiplier ses présences. C'est aussi un écran permettant de protéger la tête de l'État contre les réactions négatives de ceux qui se considèrent pénalisés par certaines décisions. Finalement, Latouche souligne que c'est à travers l'imaginaire que le leader politique commande le réel et en ce sens tout système de pouvoir implique, à la manière du théâtre, des dispositifs destinés à produire des effets. Et, écrit-il: «Pour qu'il y ait thêtre et mise en scène, il faut non seulement des acteurs et des spectateurs, mais aussi des machinistes» (p. 169).

Jean-Paul Ouellet, Robert Poupart et Jean-Jacques Simard utilisent l'expérience des CLSC pour démontrer la bureaucratisation de la culture et l'enculturation de la bureaucratie. Ils en déduisent que c'est sur la base des consensus culturels que s'élabore la rationalisation des significations partagées (les idéaux deviennent objectifs), des rapports fonctionnels de coopération entre les membres (les subjectivités deviennent fonctions impersonnelles) et des tâches (les orientations deviennent des règles, des méthodes, des pratiques routinières). Ils ont aussi constaté que les organisations deviennent les médias de l'engagement des humains dans la production de la société par la société. Dès lors, l'enjeu des luttes organisationnelles n'est plus seulement le pouvoir au sein de l'organisation, mais la place de l'organisation dans la société.

Ce volume a le mérite de nous présenter le concept de culture organisationnelle sous un jour différent de la vision purement «managérielle». Son approche est plus globalisante et permet de dégager des connaissances théoriques pertinentes. Nous aurions aimé une vision plus critique de l'exemple de Cascades au chapitre 3. Nous nous sommes demandé si cette entreprise n'avait pas atteint un degré très sophistiqué de manipulation de ses travailleurs, au point où ils se policent eux-mêmes et qu'ils soient devenus plus «cascadiens» que les fondateurs de l'entreprise.

Cet ouvrage constitue un excellent survol de différents aspects de la culture organisationnelle, mais cette question constitue un objet de recherche qui n'est certes pas épuisé. D'ailleurs, Gladys Symons nous indique quelques pistes à explorer (p. 14): le rôle de la culture dans le cycle de vie organisationnelle, l'impact des groupes d'intérêts 
sur la vie organisationnelle et, question d'éthique tout à fait d'actualité, la limite à la conscience technocratique.

Marcel Belleau

Université du Québec à Montréal 